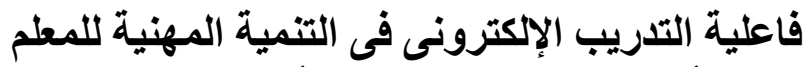

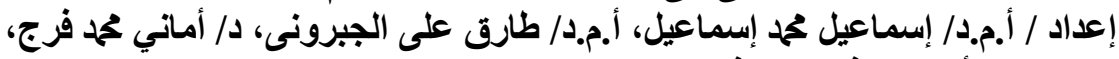

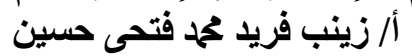

فاعلية التدريب الإكتروني في تنمية المعلم مهنيا في لغات البرمجة Effectiveness of electronic training in teacher development professionally in programming languages

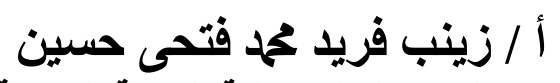

دراسات عليا بقسم تكنولوجيا التعليم- كلية التربية النوعية فئه جامعة بورسعيد

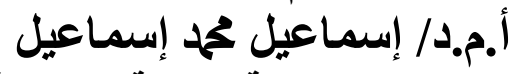

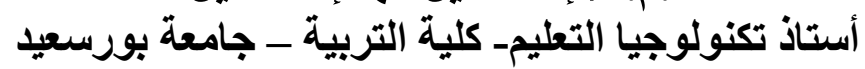

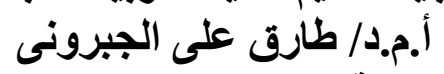

استاذ تكنولوجيا التعليم المساعد ورئيس قسم تكنولوجيا التعليم- كلية التربية النوعيةــ جامعة بورسعيد

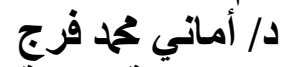

مدرس بقسم تكنولوجيا التعليم- كليّة التربية النوعيةـ جامعة بورسعيد 


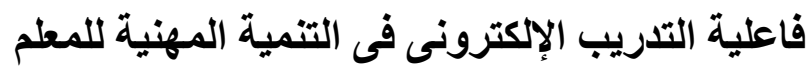

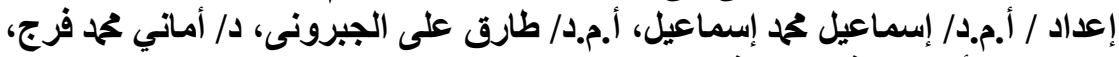

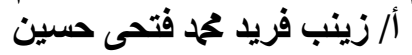

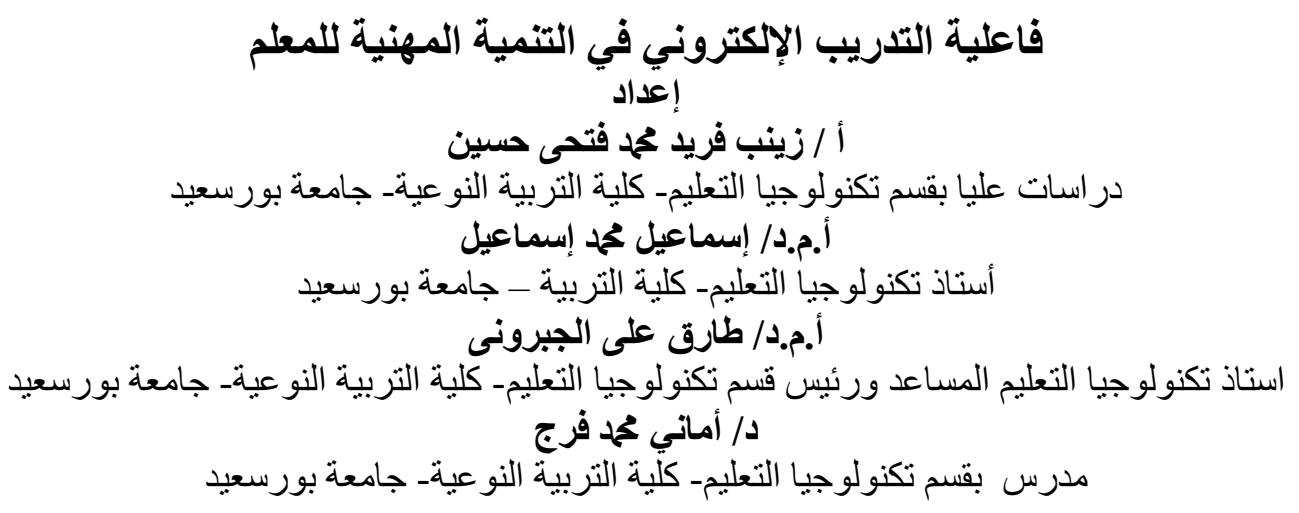

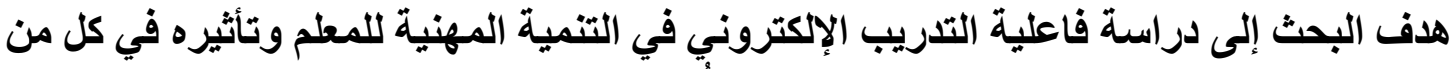

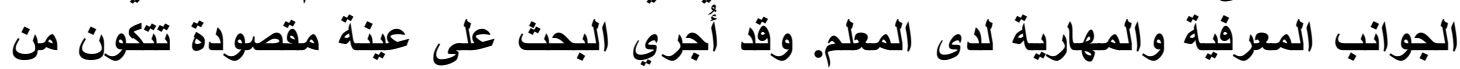

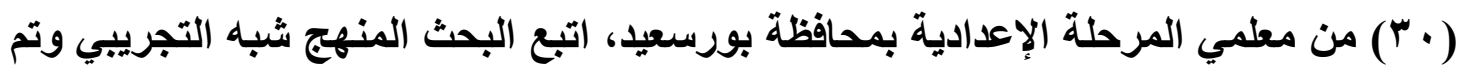

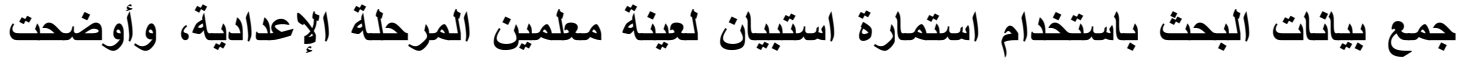

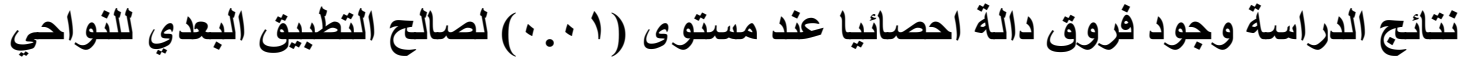
المعرفية والمهارية لاى المعلم وتأثر هم القوى بالتدريب الإلكتروني. 


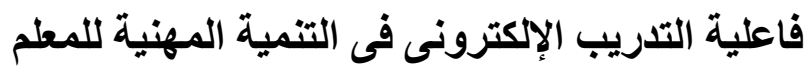

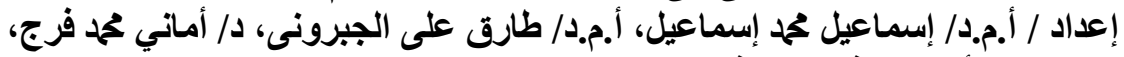

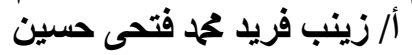

The effectiveness of electronic training in the professional

\title{
development of the teacher
}

By

Zainab Farid Mohamed Fathy Hussein

Higher Education, Department of Educational Technology, Faculty of Specific

Education, Port Said University

Prof. Ismail Mohamed Ismail

Professor of Educational Technology - Faculty of Education - Port Said University

Assistant Prof. Tarek Ali Al-Gabrouny

Assistant Professor of Educational Technology and Head of Education Technology

Department, Faculty of Specific Education, Port Said University

Dr. Amany Mohamed Farag

Lecturer, Educational Technology Department, Faculty of Specific Education, Port Said University

\begin{abstract}
:
The objective of the study is to study the effectiveness of electronic training in the professional development of the teacher and its impact on both the cognitive and skill aspects of the teacher. The research was conducted on a sample of $\mathbf{3 0}$ preparatory teachers in Port Said Governorate. The research followed the descriptive method. The research data were collected using a questionnaire questionnaire for the sample of the preparatory stage. The results of the study showed that there were statistically significant differences at $(0.01)$ The teacher's skill and their strong impact on electronic training.
\end{abstract}

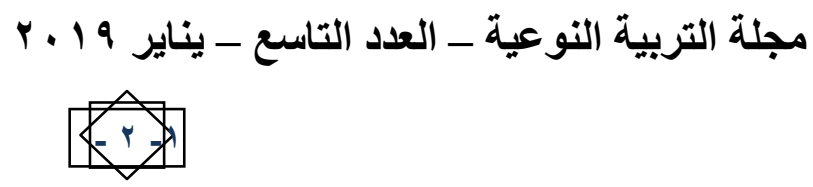




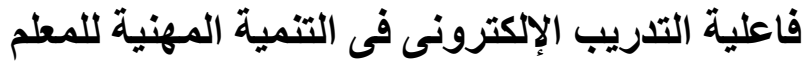

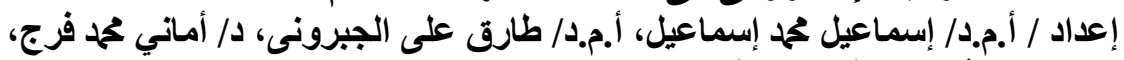

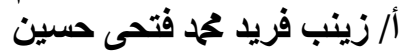

$$
\text { المقدمة ومشكلة البحث:- }
$$

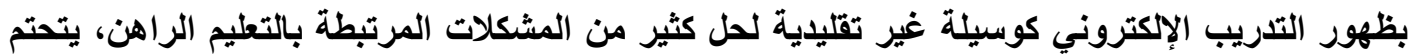

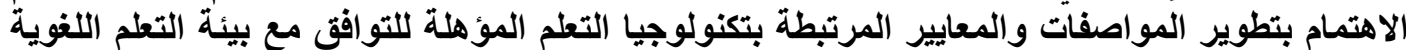

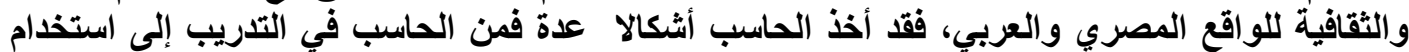

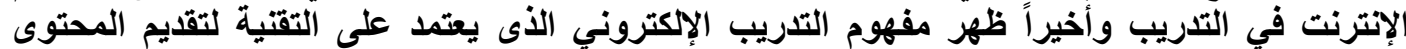

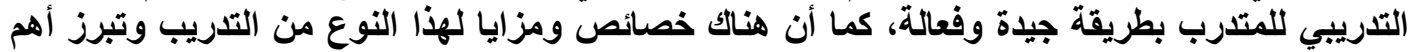

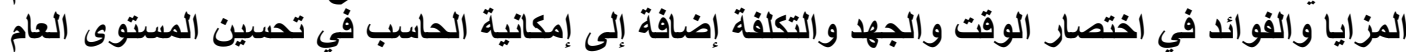

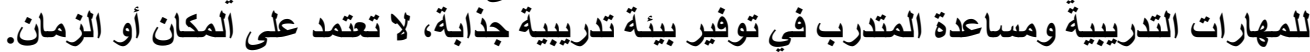

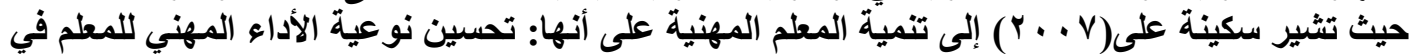

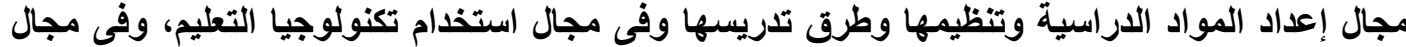

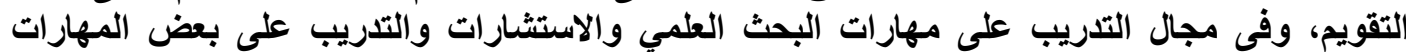
الإدارية المتوقع إسنادها للمعلم.

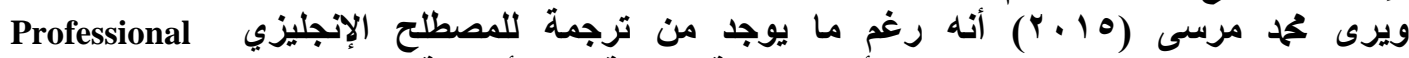
Developmental

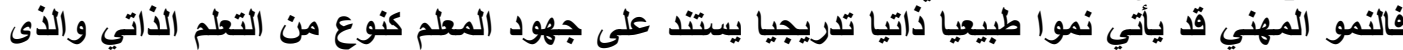

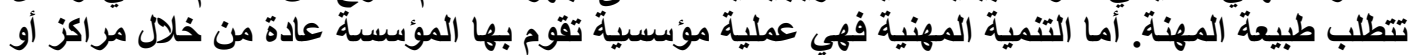

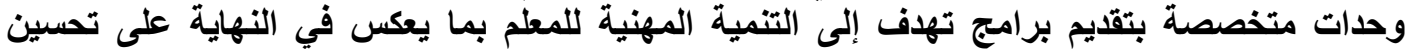

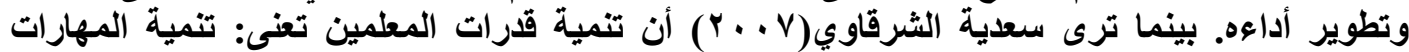

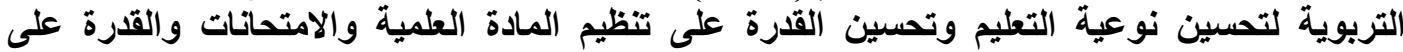

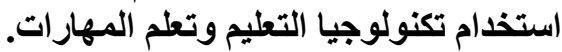

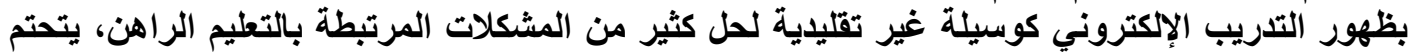

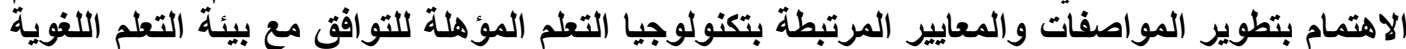

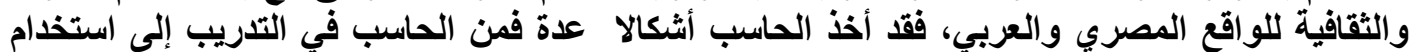

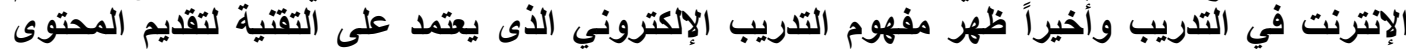

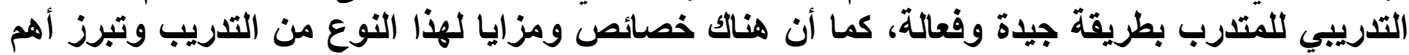

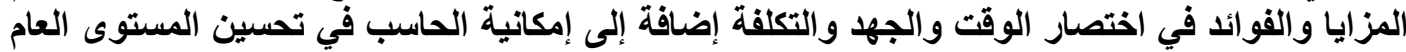

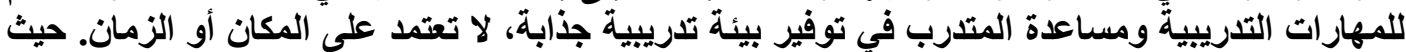

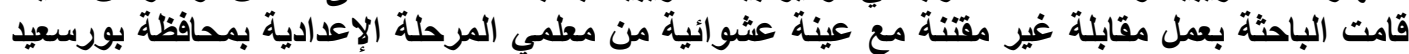

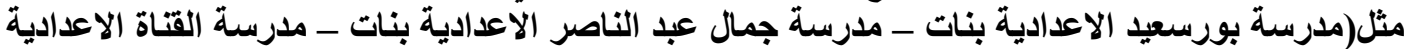

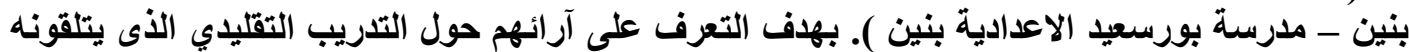
وماهى المشاكل التى يوجهونها وما مقترحاتهم في تطويرها

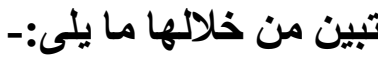
- منهم من أكد أن التدريب الآن اختلف عن الماضي فأصبحوا يستخدمون التكنولوجيا كالكمبيوتز والثرح من خلال عروض الكن تقايمية. ـ لكن لازال التقيد بالحضور في المواعيد المحددة جبريا ولا يوجد أي تدريب حر عبر الإنترنت غير

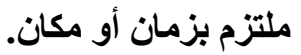

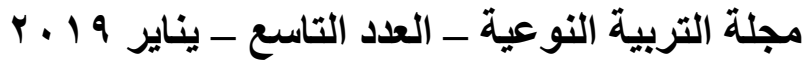
(E) 


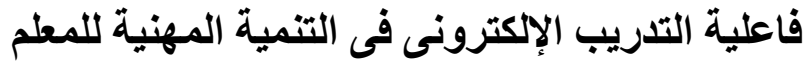

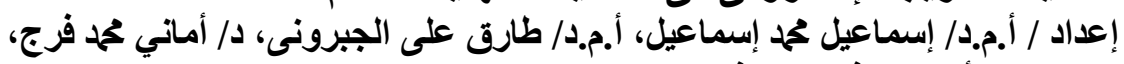

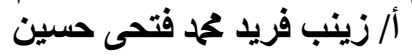

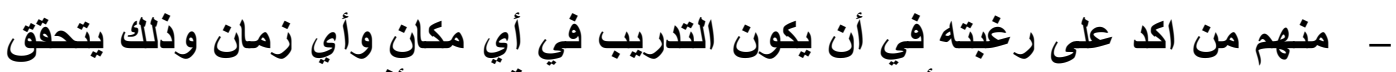

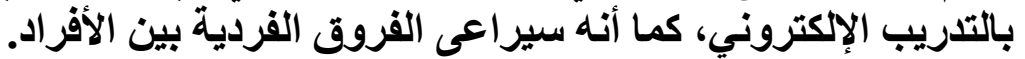

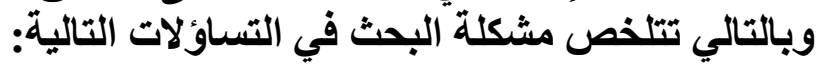

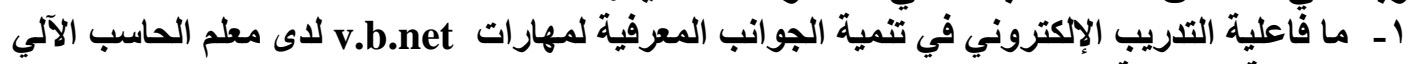

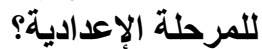
r - ما فاعلية التذريب الإكتروني في تنمية الجوانب الأدائية لمهارات v.b.net لاى مطلم الحاسب الآلي

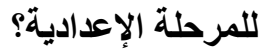

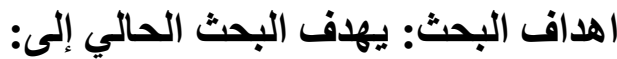
1- التعرف على أثر التثريب الإكتروني في في تنمية الجوانب المعرفية والادائية لاى المعلم بمحافظة بورسعيد. r- بيان فاعلية التدريب الإكتروني في تنمية النواحي المعرفية و الأدائية لمهارات v.b.net لاى معلم الحاسب الآلي للمرحلة الإعدادية.

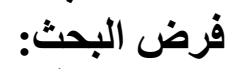

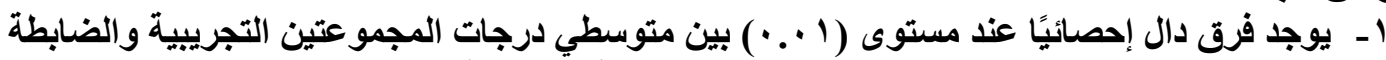

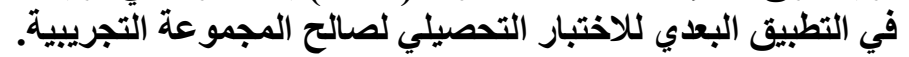

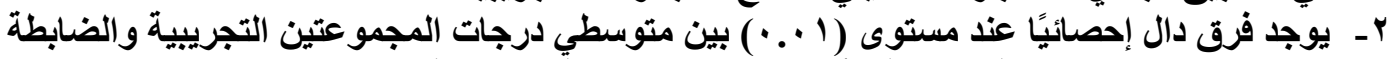

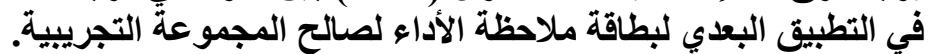
r- يوجد حجم تأثير كبير للتدريب الإكتروني أعلى من القيمة (9. . · ) في التنمية المهنية لمعلمي الحاسب

$$
\text { الآلب. }
$$

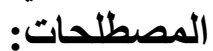

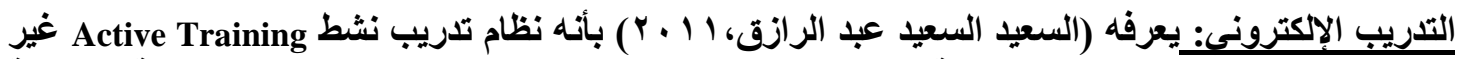

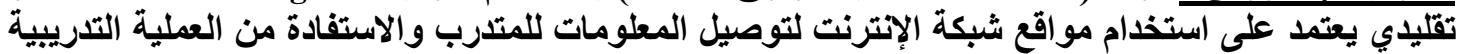

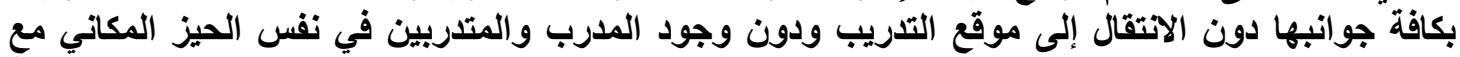

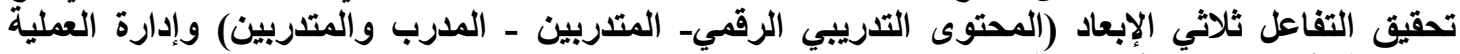
التدريبية بأسرع وقت و وأقلّ تكلفة.

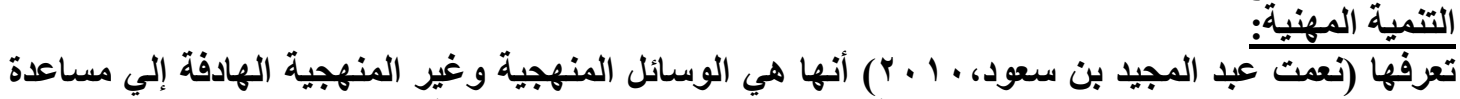

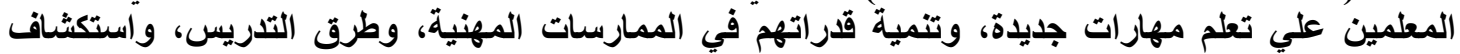

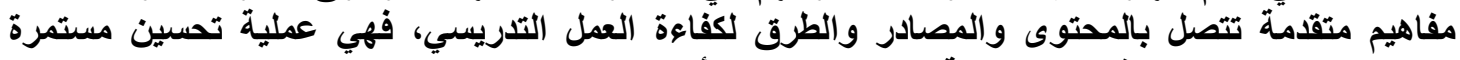
لمساعدة المعلم علي بلوغ تلوعل معايير عالية الجودة للإنجاز الأكاديمي.

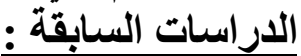

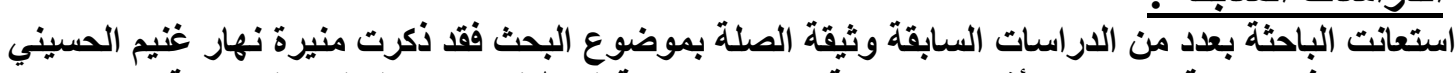

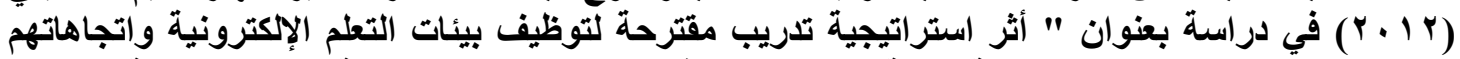

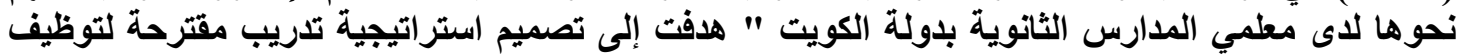

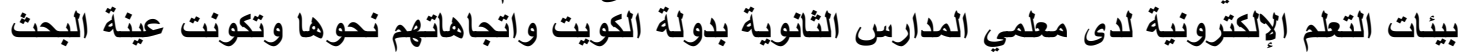

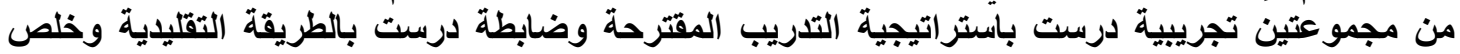

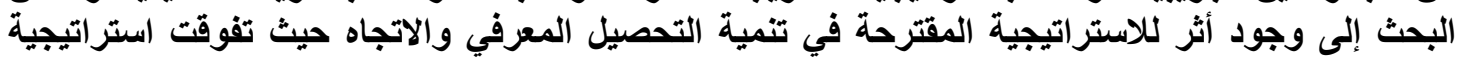

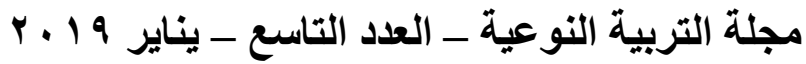
进 


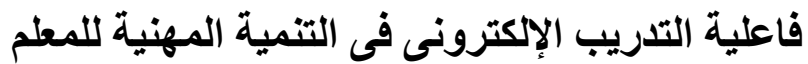

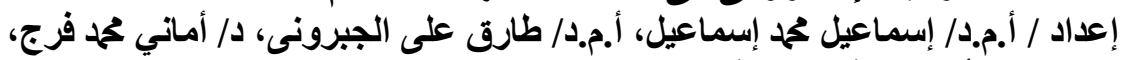

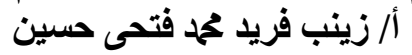

التدريب الإكترونية المقترحة على التعليم بالطريقة التقليدية في التحصيل المعرفي الإكتروني وبيئات التعلم

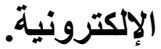

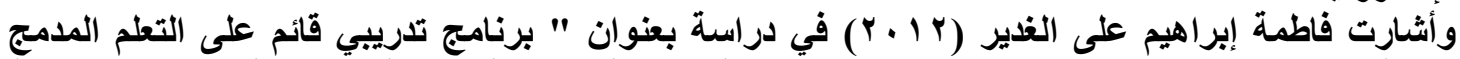

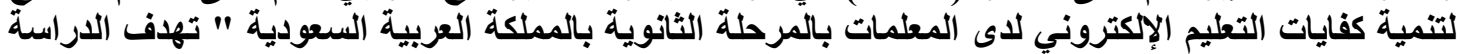

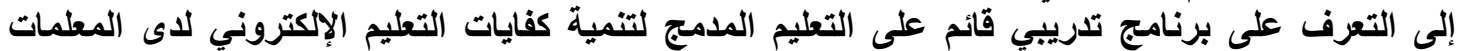

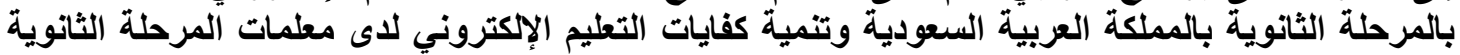

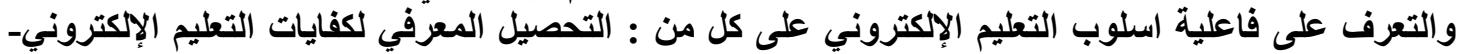

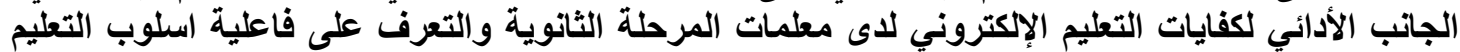

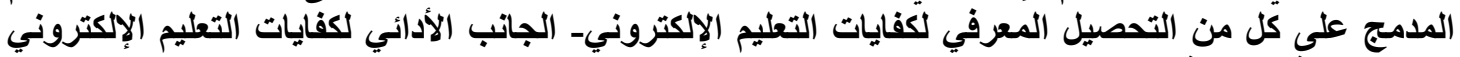
لإى المرحلة الثانوية.

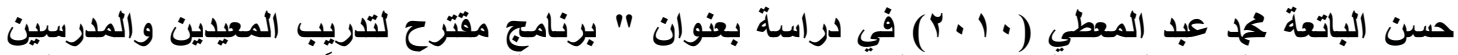

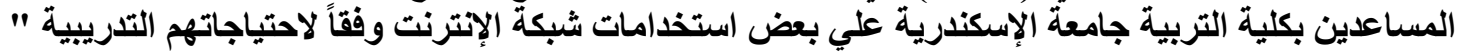

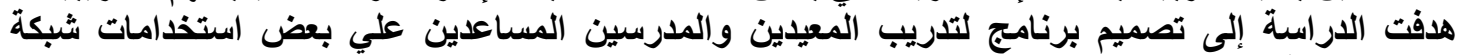

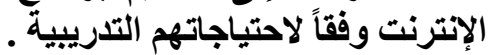

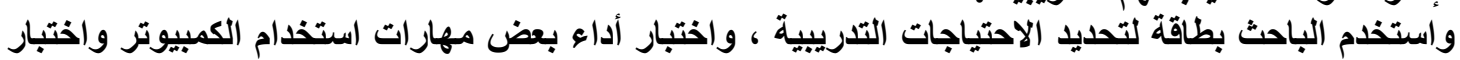

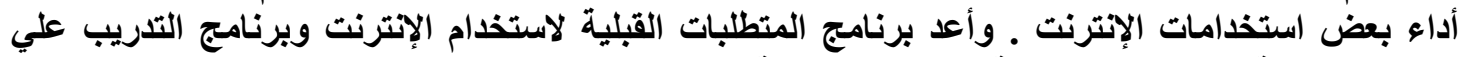

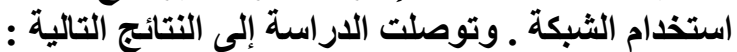

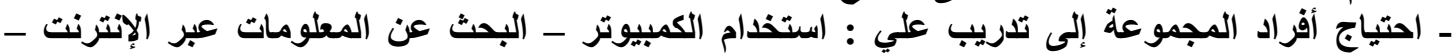

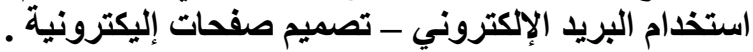

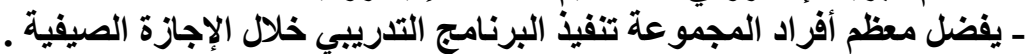

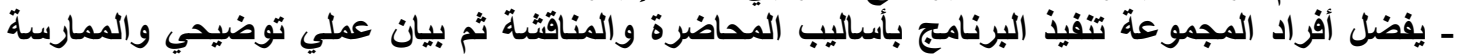

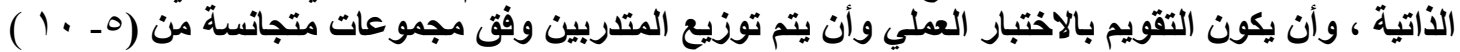

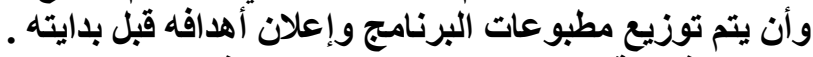

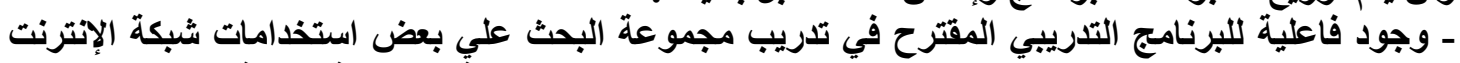

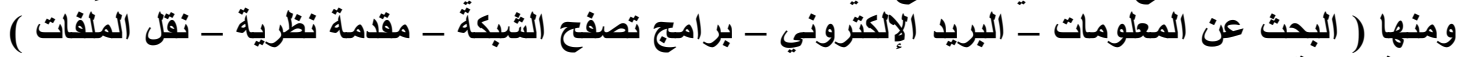

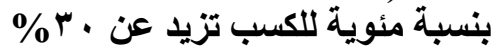

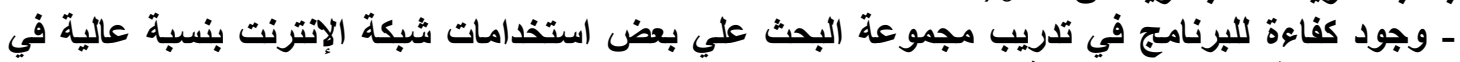

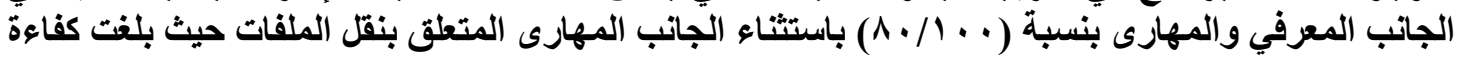

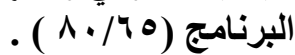

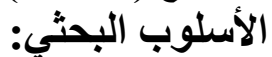
منهج البحث: الأبوني: المنهج الوصفي التحليلي:

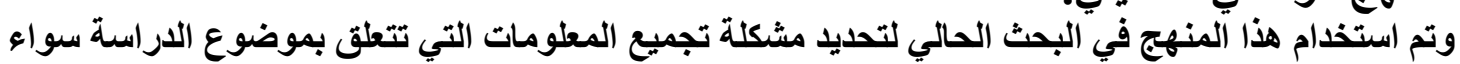

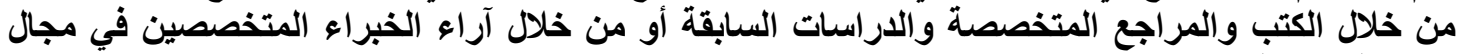
الاراسة الحالية.

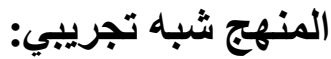
يستخدم لمعرفة أثر المتثفير المستقل (التذريب الإكتروني) على المتغير التابع (التنمية المهنية لمعلم الحاسب الآلي).

مجلة التزبية النوعية ـ العدد التاسع - يناير 9 ـ \&० 


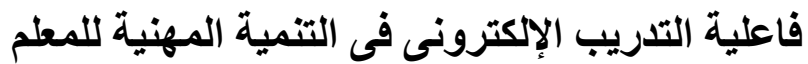

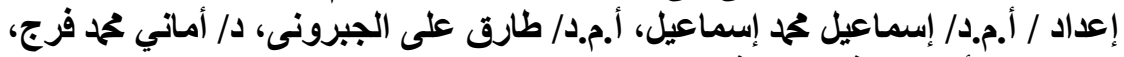

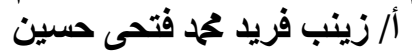

$$
\text { حدود البحث : }
$$

الحدود البثرية: تمثلت عينة البحث في عينة عشوائية من معلمي الحاسب الآلي للمرحلة الإعدادية بمحافظة

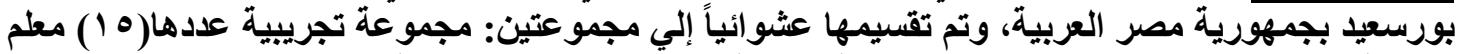

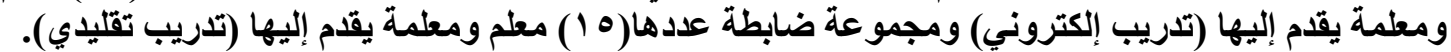

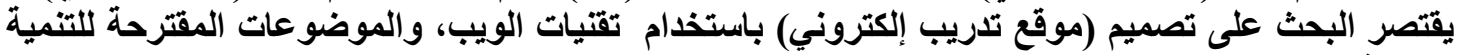

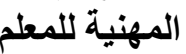
أدوات البحث:

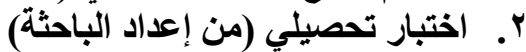

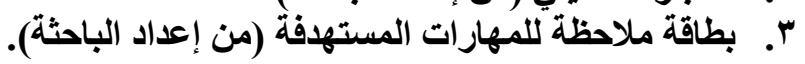

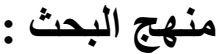
اعتمد البحث البح : الحالي على المنهجين التاليين:

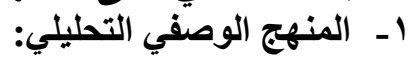

الأي يقوم بوصف ما هو كائن وتفسيره وتم استخدام هذا المنهج في البحث الحالي لتحديد مشكلة تجميع

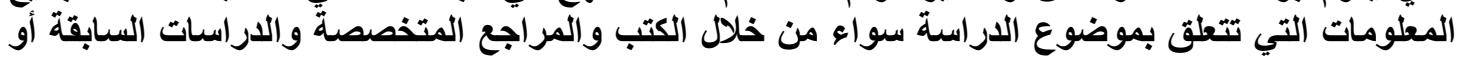
من خلال آراء ألخبراء المتخصصين بعضئ في مجال الاراسة الحالية.

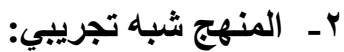
يستخدم لمعرفة أثر المتغير المستقلي:(موقع التدريب الإكتروني) على المتغير التابع (التتمية المهنية لمعلم الحاسب الآلي).

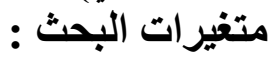

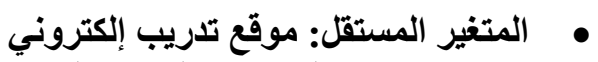
• المتفيرات التابعة : التنمية المهنية لمعلم الحاسب الآلي (الجوانب المعرفية والجوانب الأدائية). عينة البحث : عينة البحث من معثمئ ولئ الحاسب الآلي للمرحلة الإعدادية بمحافظة بورسعيد، وسوف تقسم العينة إلى مجموعتين وذلك وفقا للتصميم التجريبي كما يلي: • المجموعة التجريبية : تتلدرب تدريب الكرتوني.

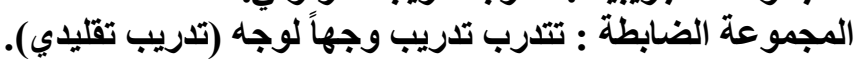
التصميم التجريبي للبحث:

\begin{tabular}{|c|c|c|c|c|c|}
\hline الملاحظة بطاقة & التحصيلي & المعالجة & الملاحظة & التحصيلي & المجموعة \\
\hline $\mathrm{Y} 1$ & 01 & $\mathrm{X} 1$ & Y1 & 01 & التجرييية \\
\hline $\mathrm{Y} 1$ & 01 & $\mathrm{X} 2$ & Y1 & 01 & الضابطة \\
\hline
\end{tabular}

جدول(1)

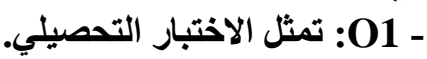

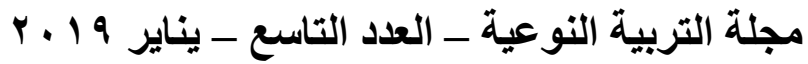
进 


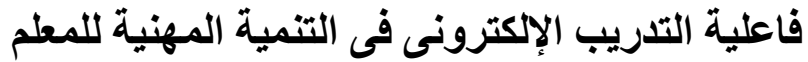

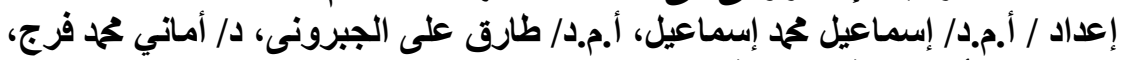

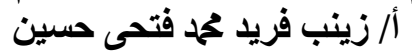

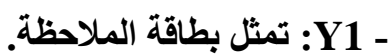 X1 -

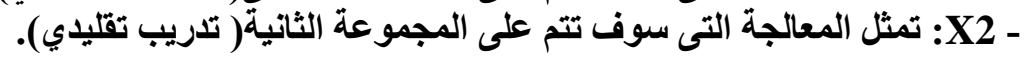

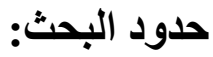

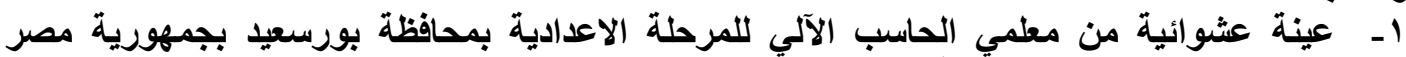

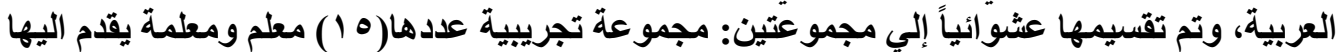

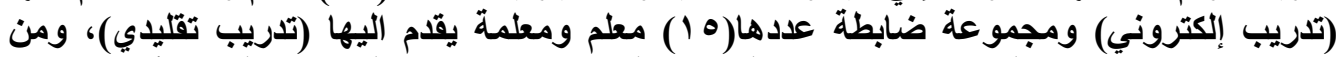

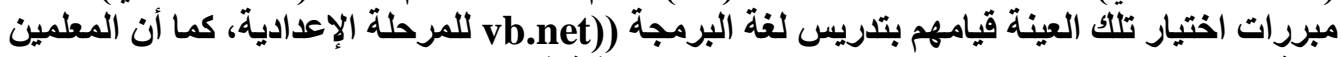

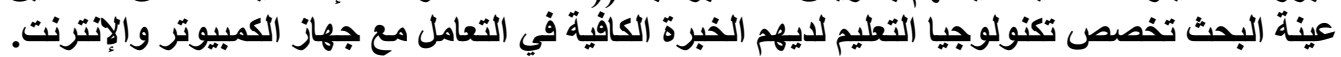

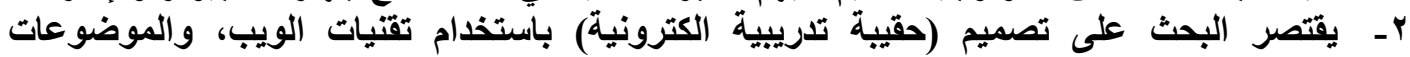
المقترحة للتنمية المهنية :- تصميم مقرر الكرتوني لغة برمجة بلهة (vb.net)، واستخذام نظام إدارة المحتوي (Moodle) و البرامج التالية:

Adobe Photoshop- Sound Forge -FrontPage - Adobe Flash - Adobe Director- Adobe After Effect - Lead video studio

$$
\begin{aligned}
& \text { أدوات البحث ومواد المعالجة التجريبية: } \\
& \text { ا. . تصميم موقع تدريب إلكتروني (من إعداد الباحثة). }
\end{aligned}
$$

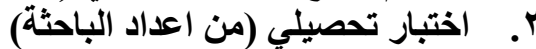

$$
\begin{aligned}
& \text { rا ب. بطاقة ملاحظة للمهارات المستهدفة (من إعداد الباحثة). } \\
& \text { إجراءات البحث: }
\end{aligned}
$$

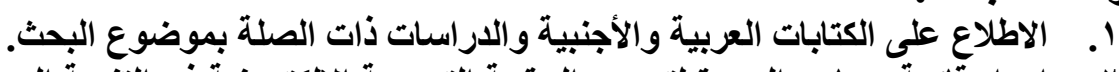

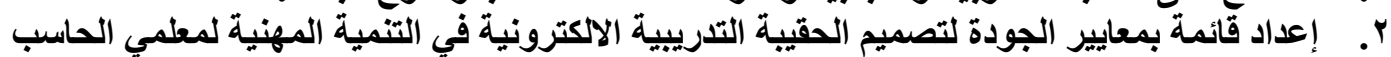

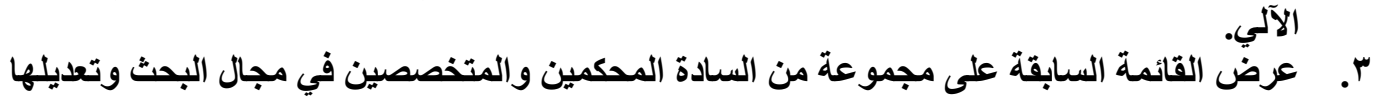
في ضوء آراء وتوجهات السادة المحكمين.

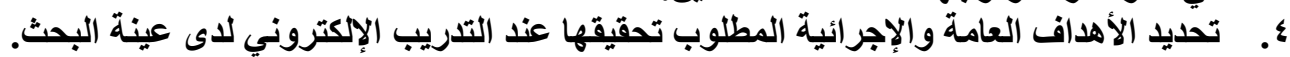

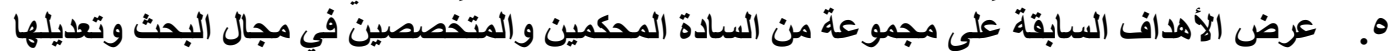
في ضوء آراء وتوجهات السادة المحكمين.

$$
\text { T. . تصميم (موقع التّريب الإكتروني). }
$$

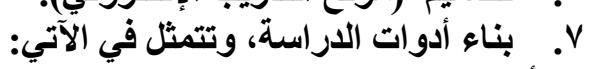

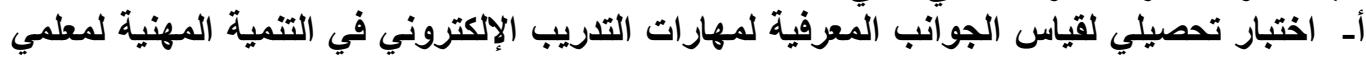

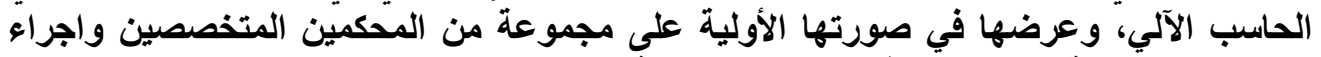

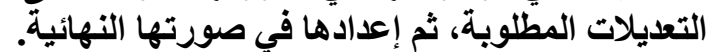

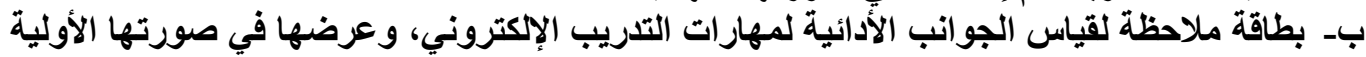
على مجموعة من المحكمين المتخصصين وإجراء التعديلات المطلوبة، ثم إعدادها في في صورتها

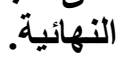

^.اختيار عينة البحث الأساسية من معلمين الحاسب الآلي بالمدارس الإعدادية بمحافظة بورسعيد،

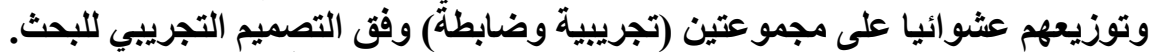
9 9. تطبيق أدوات البحث (الاختبار التحصيلي - بطاقة الملاحظة ) قبلياً على عينة البحث.

مجلة التربية النوعية ـ العدد التاسع - يناير 9 ب ب r 政 


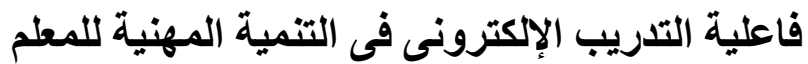

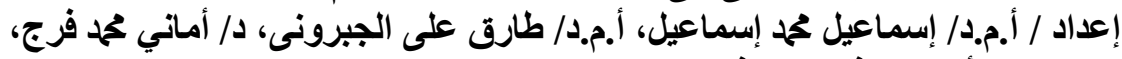

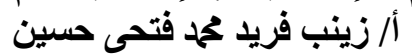

• 1. إجراء التجربة الأساسية بحيث تتعرض المجموعة التجريبية للمعالجة باستخدام التدريب الإكتروني ،

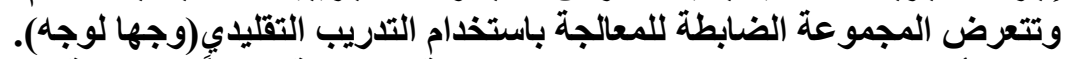

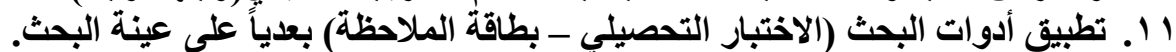

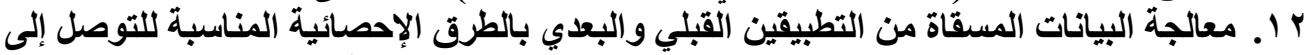

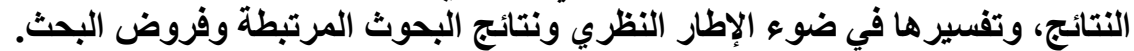

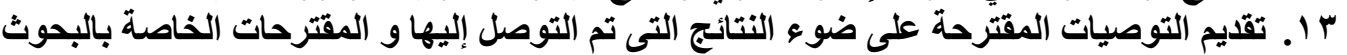

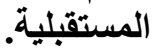

النتائج ومناقشتنها

ا- قامت الباحثة باختبار صحة الفرض الأول والذى نص على أنى أنه "يوجد فرق دال إحصائيًا بين

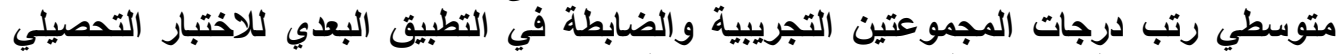

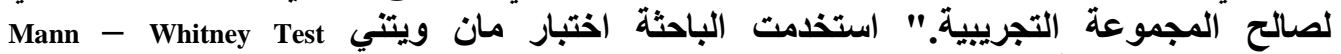

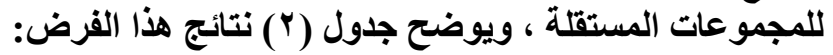

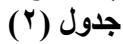

نتائج اختبار مان ويتني للمجموعتين التجريبية والضابطة في التطبيق التبعدي للاختبار التحصيلي التجريلي

\begin{tabular}{|c|c|c|c|c|c|c|}
\hline مستولة الدلالة & قيمة U U & مجموع الرتب & متوسط & 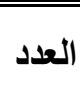 & المجموعة & المتغير \\
\hline \multirow{3}{*}{$\because \cdot 1$} & & $r r q .0$ & Tr.Tr & 10 & التجريبية & \\
\hline & 0.0 & 140.0 & $\Lambda . r v$ & 10 & الضابطة & الاختبار التحصيلى \\
\hline & & - & - & $r$. & المجموع & \\
\hline
\end{tabular}

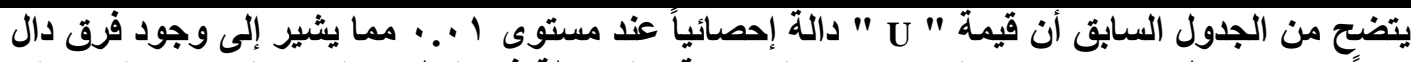

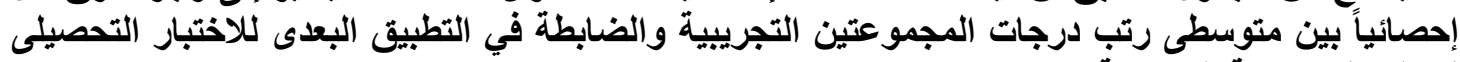
لصالح المجموعة التجريبية.

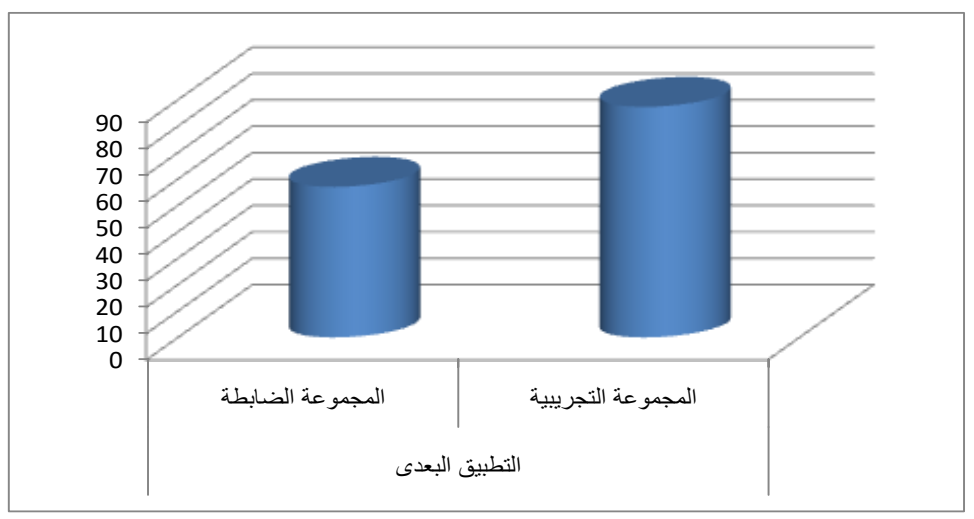

شكل (1) ش (1)

رسم بيانى لمتوسطى درجات المجموعتين التجريبية والضابطة في التطبيق البعدى للاختبار التحصيلى

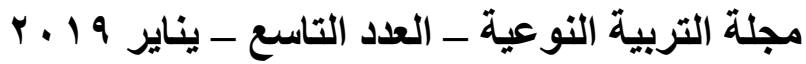
\& 


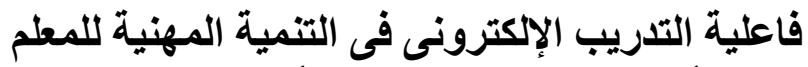

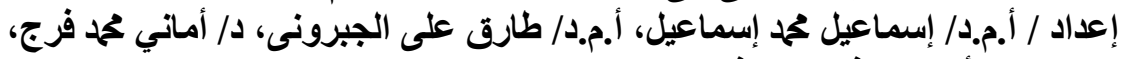

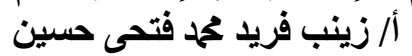

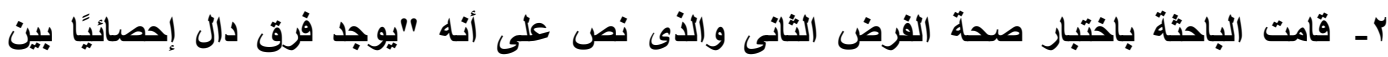
متوسطي رتب درجات المجموعتين التجريبية والضابطة في التطبيق البعدى لبطاقية البهان ملاحظة الأداء

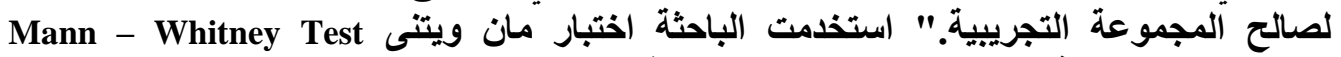

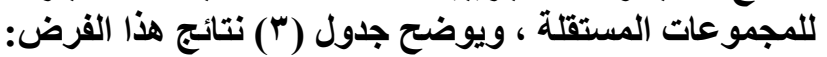
جدول (r) (r) نتائج اختبار مان ويتنى للمجمو عتين التجريبية والضابطة في التطبيق البعدى لبطاقة ملاحظة الأداء

\begin{tabular}{|c|c|c|c|c|c|c|}
\hline مستوى & قيمة U & مجموع الرتب & متوسط & العدد & المجموعة & المتغير \\
\hline \multirow{3}{*}{$\because \cdot 1$} & & $r \leqslant r .0$ & rY.q & 10 & التجريبية & \\
\hline & 1.0 & $1 \times 1.0$ & $\Lambda .1$ & 10 & الضابطة & بطاقة الملاحظة \\
\hline & & - & - & $r$. & المجموع & \\
\hline
\end{tabular}

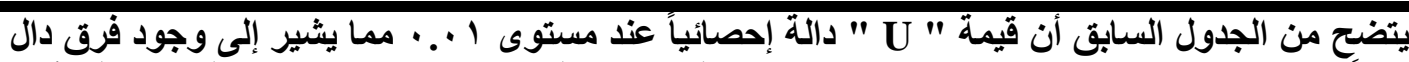
إحصائياً بين متوسطى رتب درجات المجموعتين التجريبية والضابطة في التطبيق البعدى لبطاقة ملاحظة الأداء لصالح المجموعة التجريبية.

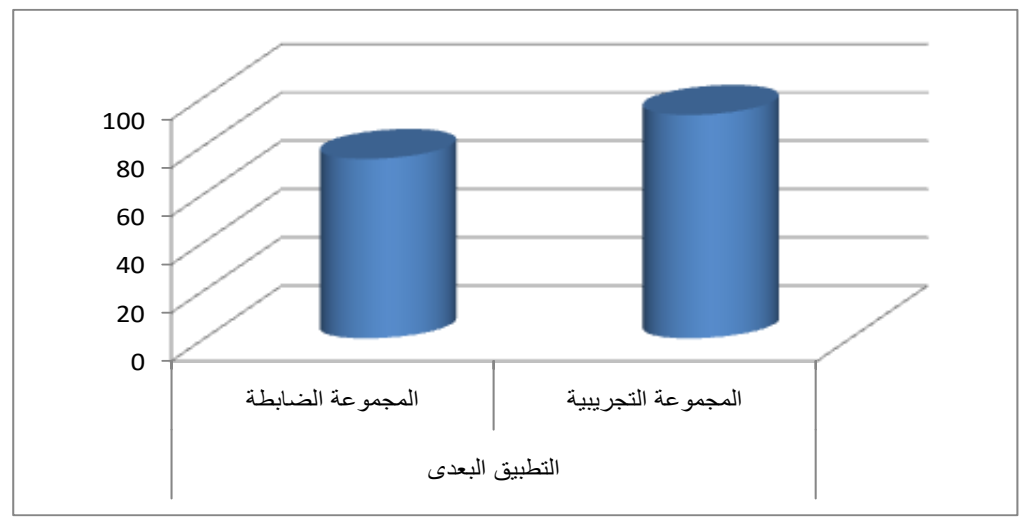

شكل (r)

رسم بيانى لمتوسطى درجات المجموعتين التجريبية والضابطة في التطبيق البعدى لبطاقة ملاحظة الأداء

r- لاختبار صحة الفرض الثالث والذى ينص على أنه " يوجد حجم تأثير كبير للحقيبة التدريبية

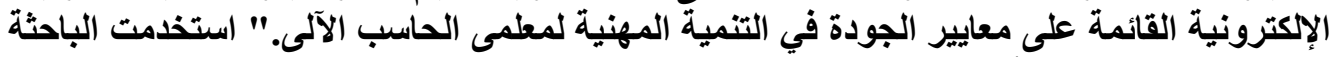

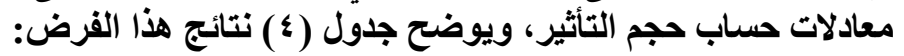




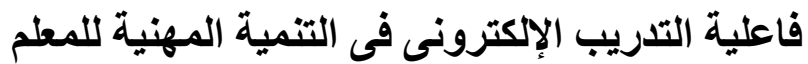

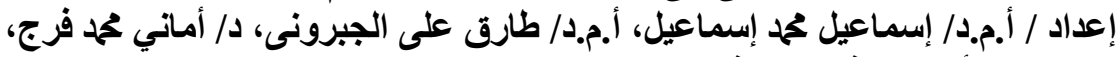

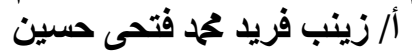

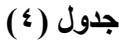

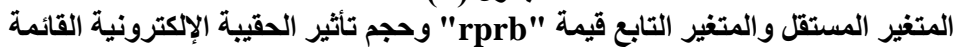
على معايير الجودة في تحسين التحصيل والأداء العملى لئي

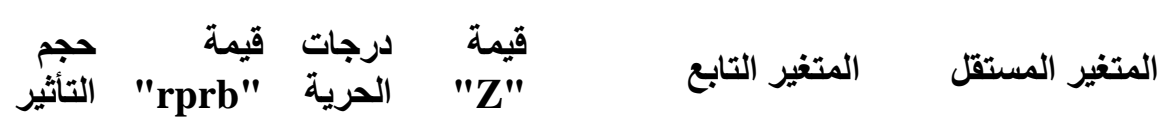

التحصيل

التدريب الإكتروني

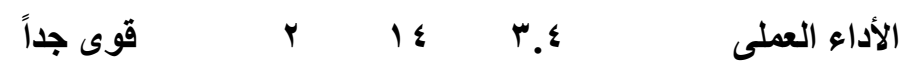

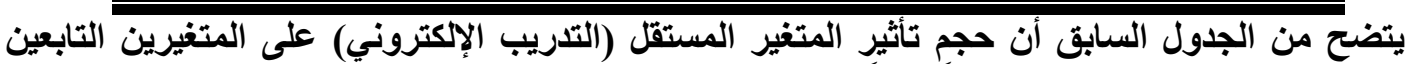

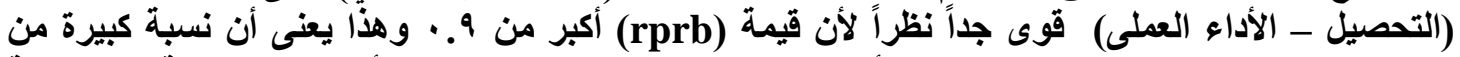

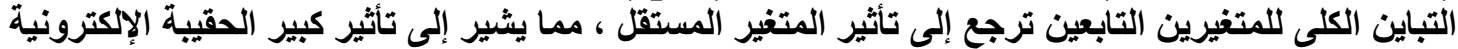
القائمة على معايير الجودة في تنمية التحصيل والأداء العملى لاى معلمي الحئ الحاسب الآلى.

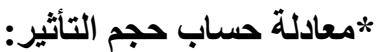

$$
\operatorname{rprb}=\frac{4(\mathrm{~T} 1)}{n(n+1)}-1
$$

حيث rprb : قوة العلاقة أو حجم التأثير T1

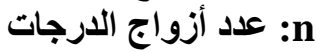

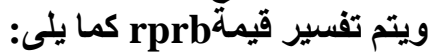

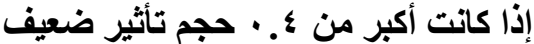

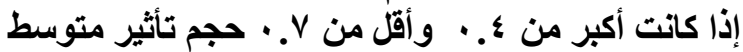

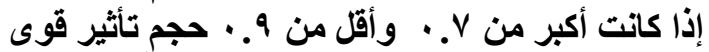

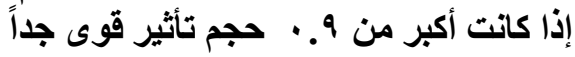




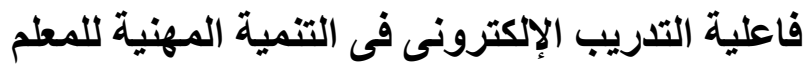

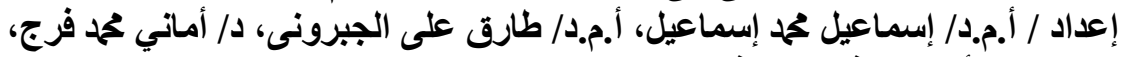

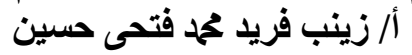

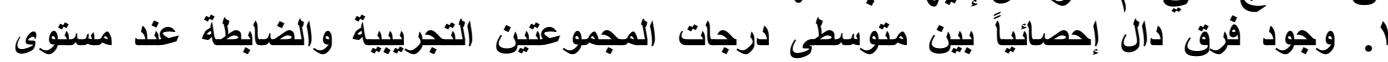

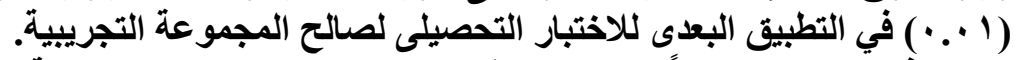

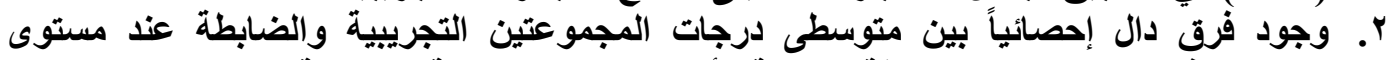

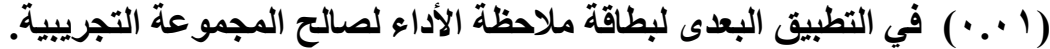

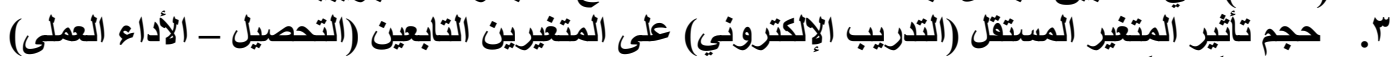

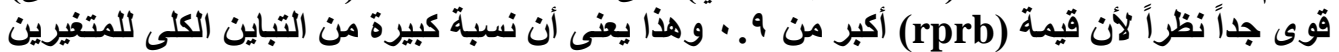

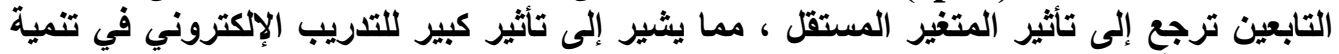
التحصيل والأداء العملى لدى معلمي الحاسب الآلى التى.

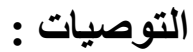

1 - ت توظيف موقع التدريب الإكتروني الخاص بهذه الدراسة في برامج تدريب المعلمين للتنمية المهنية.

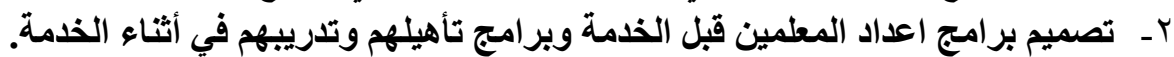

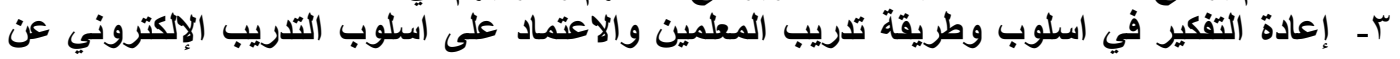
طريق التدريب الإلكتروني.

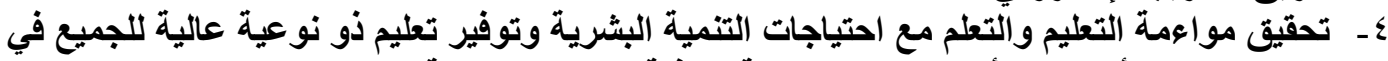

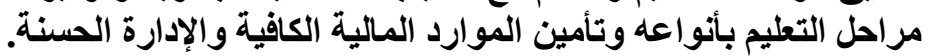

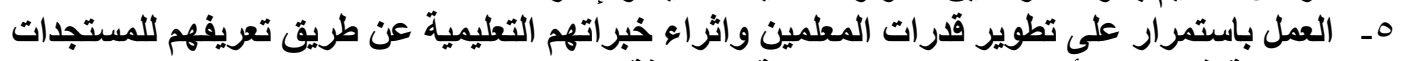

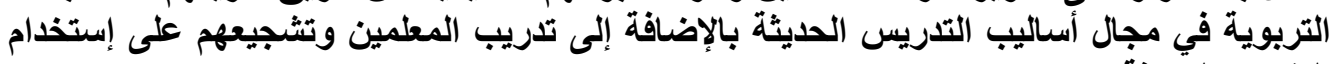

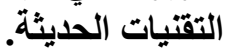




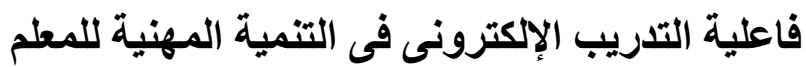

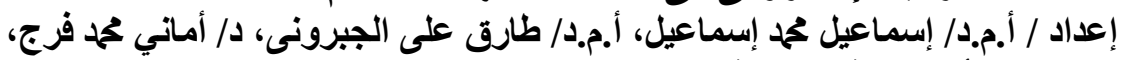

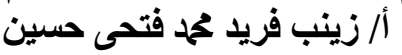

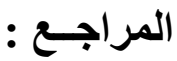

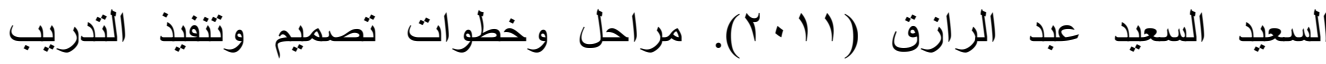
الإلكتروني على شبكة الانترنت. مجلة التعليم الالكتروني. العدد السابع.

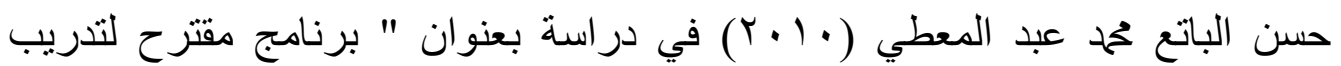

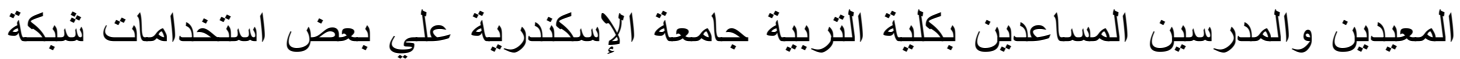

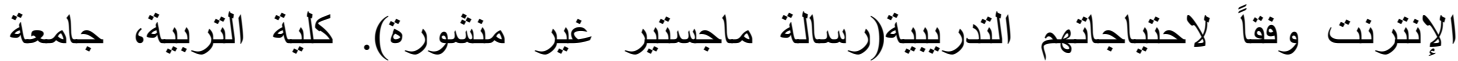

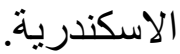

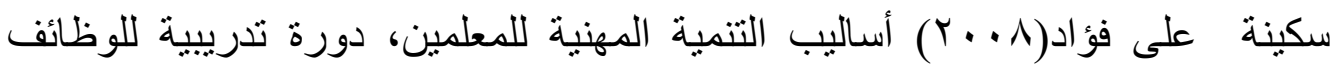
الإشر افية، وزارة التربية والتعليم، الكويت، من الموقع الالكتروني: http:// www. transparency. Org. kw. au- ti. org

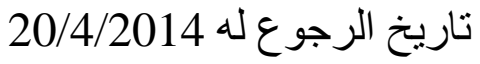

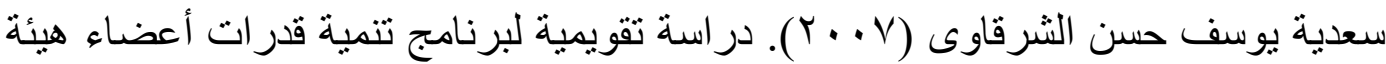

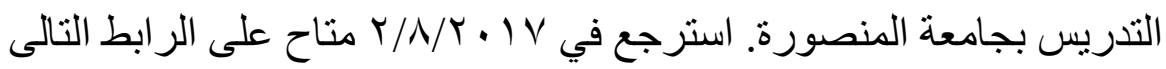

http://www.Mans.edu.eg/facedum/arabic

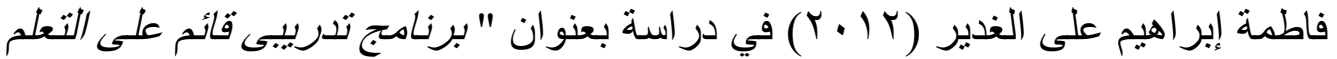

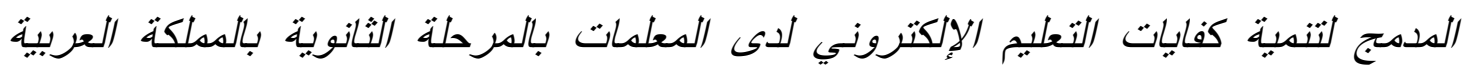
السعودية أطروحة (دكتور اه) - جامعة القاهرة. معهد الدراسات التربوية. قسم تكنولوجيا لونيا التعليم

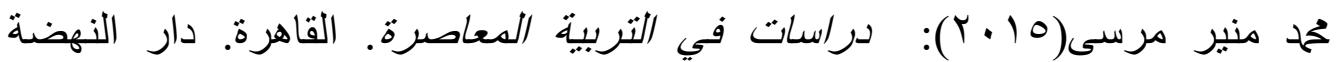
العربية.صه

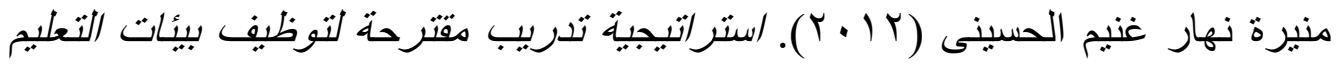

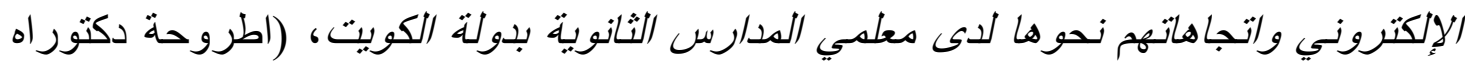
غير منشور) - جامعة القاهرة - معهد الدراسات التربوية ـ قسم تكنولوجيا التعليم والتعليم الجامعى.

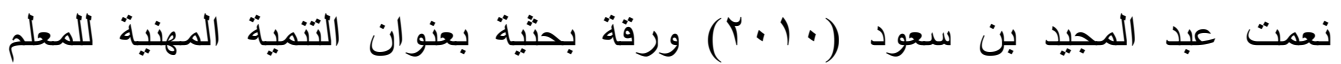
والاتجاهات المعاصرة فاعلية وتفعيل. المؤتمر العلمى حول المعلم وتحديات العصر. جامعة الفاتح

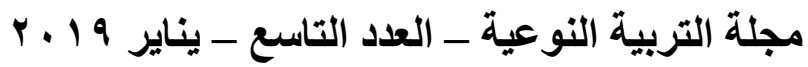
番 